\title{
ACEN and the Canadian Journal of Nursing Leadership
}

Sue VanDeVelde-Coke, RN, MBA, PhD

Executive Director

CARE Centre for Internationally Educated Nurses

Toronto, ON

Chair, Editorial Advisory Committee

Canadian Journal of Nursing Leadership

The Canadian Journal of Nursing Leadership (CJNL) will soon celebrate 30 years of publication. Many readers may not be aware that $C J N L$ is the official journal of the Academy of Canadian Executive Nurses (ACEN). The journal came into existence in the early 1990s and was published independently by ACEN prior to Longwoods Publishing taking over in 2003. Throughout the decades, ACEN has continued to be involved with the journal, providing input to the publishers through the Editorial Advisory Committee. The purpose of the Editorial Advisory Committee is to provide advice and feedback to the editorial team of CJNL to ensure that the publication maintains relevance, currency and value to its nursing leadership stakeholders and audience. During the past year, the Committee has made a number of important changes.

\section{New Terms of Reference for the Editorial Advisory Committee}

In 2016, new Terms of Reference were approved by the ACEN Executive Committee. The new responsibilities of the members of the committee include: providing guidance and feedback that support the journal's strategic direction; reviewing the statistics of the journal's readership; assisting Longwoods' CJNL editors in engaging stakeholder feedback regarding satisfaction with the journal; and engaging nursing leaders to review, solicit and submit relevant papers. 
The membership was also renewed to include nursing leaders who represent:

- nursing service administrators;

- nursing education;

- nursing regulation;

- researchers who focus on leadership and management in health services;

- nursing leaders with a business acumen;

- emerging nursing leaders; and

- nursing leaders from outside Canada.

The members represent the major regions of Canada as well as nurse leaders globally. The term is for two years, with one term renewal. The new members were approved by the ACEN Executive in June-July, 2016; the Editorial Advisory Committee now includes the following members:

- Sue VanDeVelde-Coke, Chair (ON)

- Alex Harris (ON)

- Alison Kitson (Australia)

- Kirsten Krull (ON)

- Barb Mildon (ON)

- Sheri Lynn Price (NS)

- Nancy Purdy (ON)

- Walter Sermeus (Belgium)

- Lynn Stevenson (BC)

An additional major change in the Terms of Reference is that the term "Editorial Advisory Board" was changed to "Editorial Advisory Committee." The word "Board" was considered incorrect, as the group does not function as a board in terms of governance functions, but rather as a committee in terms of functions and responsibilities.

\section{New Publishing Agreement with Longwoods Publishing}

This past year, a complete review was undertaken by Longwoods Publishing, the journal's Editor-In-Chief and the chair of the Editorial Advisory Committee, and a new publishing agreement was put in place.

One major change to the agreement is that Longwoods will operate the journal as a profit-making publication via subscriptions, advertising and special or sponsored issues. This means that the liability for the financial status (i.e., profits and losses of the journal) rests with Longwoods. ACEN is not in a financial position to accept financial liability for the journal. 
Key responsibilities for ACEN in the agreement are to appoint the Editor-InChief of the journal, to provide feedback to the publisher and the Editor-In-Chief regarding topics of interest for the journal, and to submit a quarterly column to the journal as an update on ACEN's activities.

\section{Thanks to Our Editor-In-Chief}

On behalf of the Editorial Advisory Committee, I would like to thank our EditorIn-Chief, Lynn M. Nagle, who continues to do an excellent job producing firstclass editions of CJNL. Under her leadership, the journal's emphasis has changed to "topic-based" editions, allowing interesting debates and perspectives on one topic to be presented in an edition. Recent topics included the care of the chronically ill, advances in informatics and leadership. Other editions coming in 2017 will focus on nursing leadership in home and community care, mental health and quality improvement.

Thank you, Lynn, for the leadership you have shown in continuing to make CJNL a respected and sought-after publication focusing on nursing leadership, the only one of its kind in Canada. I also wish to acknowledge and thank Lynn's editors, who assist her in creating each edition: Lianne Jeffs, Editor of Practice; Gail Tomblin-Murphy, Editor of Policy and Innovation; and Carol A. Wong, Editor of Research.

\section{Join the conversation}

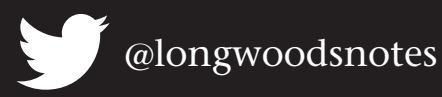

YouTube youtube.com/LongwoodsT

(2) pinterest.com/longwoods

facebook.com/LongwoodsPublishingCorporation 